\author{
Multidisciplinary \\ SCIENTIFIC JOURNAL OF \\ MARITIME RESEARCH
}

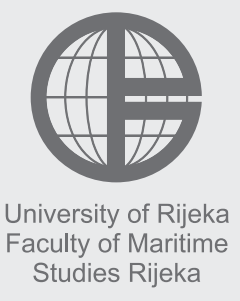

\author{
Multidisciplinarni \\ znanstveni časopis \\ POMORSTVO
}

\title{
Improving the coastal line passenger traffic management system by applying information technologies
}

\author{
Deša Rathman ${ }^{1}$, Edvard Tijan², Alen Jugović ${ }^{2}$ \\ ${ }^{1}$ Celebes IT d.o.o., Grebenska 19, 20000 Dubrovnik, Croatia \\ ${ }^{2}$ University of Rijeka, Faculty of Maritime Studies, Studentska 2, 51000 Rijeka, Croatia, e-mail: etijan@pfri.hr
}

\section{ARTICLE INFO}

Preliminary communication

Received 2 May 2016

Accepted 27 May 2016

Key words:

Passenger traffic management

Coastal line system

Information technologies

\section{Introduction}

The need to increase the efficiency of the national system of public maritime transport services management derives from the characteristics of the environment, i.e. wider economic environment. In order to equalise the conditions for the economic development of islands with those of the mainland, an efficient coastal liner service is necessary [7]. The national public coastal liner shipping system is of strategic importance for Croatia, because it is the prerequisite for transport connection of the islands, and thus the demographic trends and economic development (tourism in particular). For these reasons the state pays special attention to this public transport system, and sets the minimum requirements. The public principle however does not exclude the economic principle of business. The globalization and internationalization trend becomes an increasingly relevant environment moderator, driven primarily by the inclusion of Croatia in the European integration processes. The successful coping with pronounced market principles within the rapidly changing business dynamics is becoming a necessity for all operating entities within the system, and the criteria that must be reckoned with by the management. Implementation of modern management and valueoriented concept implies the establishment of the feedback principle and continuous improvement through a high level of system integration. The requirements of all stakeholders have to be assessed, as well as internal and external factors in the continuous market positioning and maintaining of competitiveness. Information technologies and the appropriately designed information system, combined with standardized system elements, are an essential foundation and the basis of functionality of these principles. The ultimate aim should be the advancement of the quality level of maritime passenger transport service as a public good, and realization of higher level of efficiency, together with stability and business continuity assurance [6].

\section{Features of the public coastal liner shipping and review of public transport services in Croatia}

Public transport in coastal shipping is the transport of passengers, cargo and vehicles in Croatian internal waters and territorial sea, to be performed on pre-established lines according to published conditions of sailing schedule and price list [3]. Passenger state liner transport service in the Republic of Croatia is carried out by 12 different shipping companies. Together, these companies provide coastal service in 94 different ports alongside Croatian coast. Of these 94 ports, 22 of them are mainland ports while other 72 ports are island passenger ports located on 43 islands [7]. 
The line is a route or a set of routes from the beginning to the end of transport, at which the transport of passengers, cargo and vehicles is performed according to a published timetable, with one or more vessels [3]. According to the importance of the route, the lines used for public transport are divided into national lines, county and intercounty lines, and local lines. Coastal liner service is characterized by an intense seasonality, with maximum of traffic during the summer months [7].

Maritime line transport system in Croatia includes public transport of passengers and vehicles on the routes to which the concession to the shippers have been issued by authorized public institutions. The functioning and the basic elements of the system are regulated by the Act on Transport in Liner Shipping and Occasional Coastal Maritime Traffic. The purpose of the system is to provide a regular connection of inhabited islands with the mainland, inhabited islands with each other, and settlements on the mainland, with the appropriate number of daily connections in both directions in order to create better life conditions on the islands and to encourage island development [7].

The central managing and administrative body of the system is the Coastal Liner Service Agency (Agencija za linijski obalni pomorski promet), a non-profit legal entity that is engaged in the tasks related to concession granting for public transport on national lines, and other tasks defined by the Act.

The establishment of the public transport system is based on the following principles:

- promotion of economic development on islands,

- continuity and regularity of transport with the ships of a certain capacity and type, and ensuring adequate quality of transport,

- transport services with a predetermined price and other conditions, particularly for certain categories of passengers and for certain lines,

- providing support to shippers, without which it is not possible to ensure the continuity and regularity of public transport on certain routes,

- adapting public transport to the real requirements,

- providing additional transport services.

\section{The seaport system - acceptance of vessels and passengers in the port}

Construction, maintenance and management of ports open to public transport is conducted through Port Authorities. The Republic of Croatia established six port authorities for ports of special (international) economic interest and 22 port authorities for ports of county importance [1]. The ways of port management and the organization and structure of port authorities are dependent on the classification of ports with regard to their importance in the transport system and seaport system of the Republic of Croatia. It is also conditioned by the volume of seaport traffic, the condition and size of seaport capacity and sea- port connections with the hinterland. Port Authority's role is the management of strategic port development, management of seaport use, ensuring the smooth flow of traffic through the coordination of entities operating in the port area, the maintenance of port infrastructure, management of seaport capacity investments and finally the control and management of private sector activities by issuing concessions for certain activities [2].

Although not directly responsible for activities in the process of public coastal liner service, port authorities have an important regulatory role, due to dynamic interactions between the system of public liner shipping and port system management and operations. There are two areas within which this interaction takes place:

- the organization of the seaport area,

- the acceptance of ships and passengers in the seaport.

The acceptance of ships and passengers in the seaport, apart from the described operational level, also refers to the administrative management and coordination level. Acceptance of ships and passengers/cargo/vehicles in the port is an integrated procedure involving several stakeholders (holders of various activities and functions). Therefore, a software solution to support this process must ensure communication between all those stakeholders and activities, according to the set rules and document/information flow. In documentation and functional sense, the process of accepting the vessel begins by announcing the vessel arrival, on the basis of which the port authority issues a certificate of reservation. The required data/reports are distributed to other relevant entities or stakeholders involved in the process of accepting the vessels.

\section{Business processes within the system of public line transport services}

Within the system of public coastal liner services, the following groups of processes can be singled out (Figure 1):

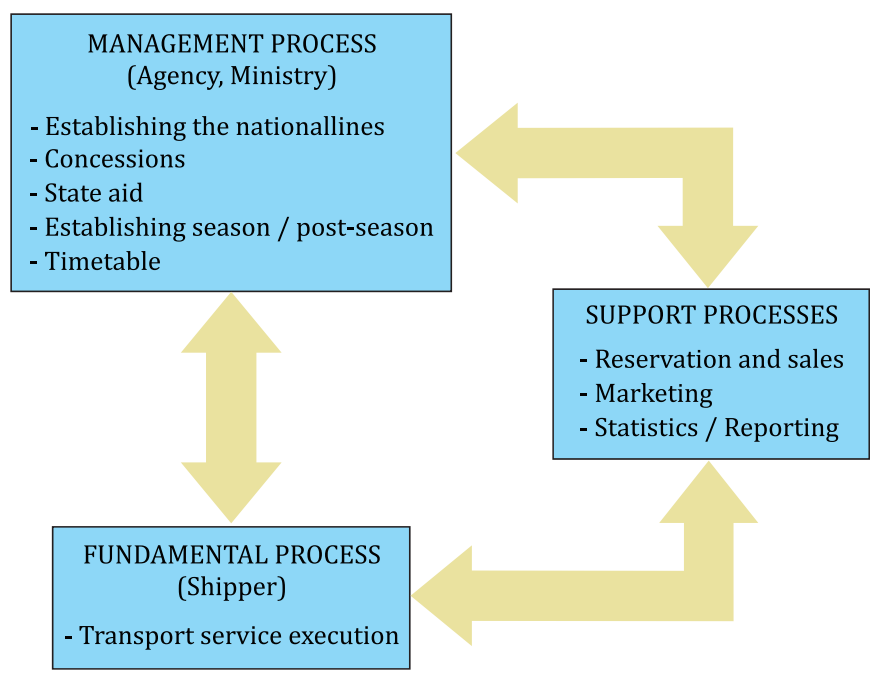

Figure 1 The system of public coastal liner services 
- the management process,

- the fundamental process (the process of transportation of passengers),

- support processes to the fundamental process (booking and ticket sales, ship tracking, etc).

\subsection{The management process}

The bearer of the management process is the Coastal Liner Service Agency. Its activity is defined by the following tasks:

1. Activities related to the granting of concessions for national lines: a public tender procedure, decisions on granting and revoking concessions, the signing of the concession agreement, cancelling of public tenders, transfer of concessions to another shipping company, approval of a replacement vessel in the event of force majeure or failure to meet the set conditions, the concession extension in the case of repetition of a public tender, approval of the price list of services, approval of the timetable.

2. Granting preliminary approval to decisions regarding county, inter-county and local lines.

3. Determining seasonal and off-seasonal periods of navigation.

4. Unifying the timetables.

5. Monitoring the implementation of the provisions of the Law, the decision and the concession agreement, in relation to state support and the payment of concession fees for national lines.

6. Other tasks legally entrusted to the Agency.

From the legal definitions of activities, the control mechanisms of coastal line shipping system management arise as follows:

1. Establishing the national lines:

- minimum trip frequency,

- type and capacity of the ship,

- modes of transport.

2. Concessions:

- tender conditions,

- terms of contract,

- selection criteria.

3. State aid:

- determination of criteria for state aid,

- approval and control of state aid allocation,

- establishment and management of the system of awarding and exercising the right to subsidized tariffs.

4. Establishing season and post-season.

5. Timetable:

- participation in adoption or changes of timetables,

- timetable unification and updating.
In order to effectively implement the control mechanisms, is necessary to establish a feedback mechanism between the planned and actual values within the control system. The organizational assumption is as follows: to establish the planning and control functions, the organization of measurable objectives hierarchy, and accordingly the planned values. The intensification of relations between functions is necessary in the direction of planning - implementation - control - intervention, in order to implement the process approach to management, which is a precondition of system efficiency. The process approach ensures the recognition and valuation of the role of data in the place of its origin, in the context of the functioning of the system and its individual parts, and the design and positioning of information as input variables in accordance with the wider context, the objectives and purpose. The process is a set of activities and/or operations that transform certain input into output values [5].

The advantage of this approach is the continuous management that it provides through connecting individual processes within the system of processes, as well as through their combination and interaction. Bridging the boundaries between processes is the basis for the integration and harmonization of the system elements, as well as for the construction of a functional management information system. Allowing to directly discern the relationship between input and output, the process organization is fundamental for the operation of continuous improvement.

The information flow designed in accordance with the above principle is actually the establishment of a sequence of converting input into output according to pre-defined stages of the process.

\subsection{The fundamental process (transportation)}

The flow of information and activities is established from the lowest operational level and is a prerequisite for successful design of management mechanisms. The fundamental process (transportation) consists of a series of operational activities in which it is crucial to implement a unified process flow. The following are the stages in the fundamental process (transportation):

- travel itinerary,

- ticket purchase,

- login, registration, check-in,

- boarding preparation,

- boarding,

- navigation,

- disembarkation.

The performance of the fundamental process and the level of its effectiveness are based on management instruments designed as part of the management process. Execution of the transport service combines actions from different stakeholders which take turns at different stages of the process, namely: 


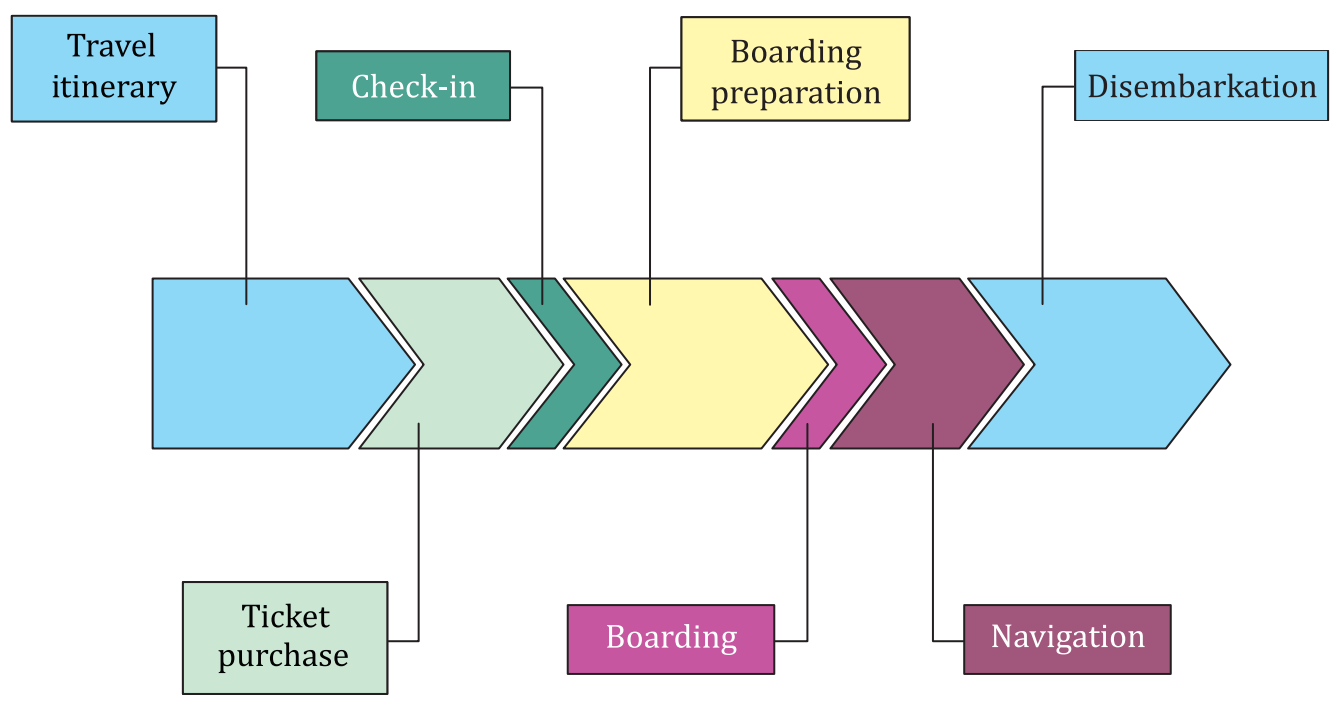

Figure 2 The fundamental process (transportation)

- agencies for booking and ticket sale,

- shippers,

- port operators.

The application process, registration or check-in, admittance in the boarding area, and embarkation preparations is performed if necessary, which is mostly conditioned by high intensity of traffic or a larger number of lines per port, and is dependent on spatial and organizational capabilities of the port.

Disembarkation is the last phase of the execution of transport services. It is necessary to determine where disembarkation ends, as well as the liability of the shipper towards the passengers. Depending on the circumstances of the individual travel/line, certain phases (reservation, registration and embarkation preparation) do not have to be a part of the process.

\subsection{Support processes}

The two main support processes are the purchase/ sale of tickets and the event logging of service execution. Together they create a reporting database. Buying and selling of tickets is conducted through the ticket agency or travel agency (with which the shipping company signed a contract of sale), or directly online. This activity is directly related to the user, therefore it directly affects the quality and efficiency of transport services. Queues when buying tickets just before the trip should be avoided, and reservation options should be available. The introduction of online sales and prepaid services greatly contributes to reducing this problem.

\subsection{The shortcomings of the existing system}

Inefficiencies and shortcomings that occur within the system of public line transport services occur in relevant mechanisms and instruments of control, and, consequently, the basic process of service execution (transport). Control instruments should be developed on the basis of appropriate organizational background, to form a documentation-organizational unit as a support to the implementation of a centralized management system.

Due to the mass and dynamic elements at the operating level that are the object of regulation and management, the ability to use real-time data in business events from which they derive has an important role. Therefore, the application of information technology, as well as a single, integrated information system (with an appropriate organizational background) is a necessary precondition for the improvement or introduction of particular functions.

From the viewpoint of the management process, the main shortcomings relate to the limited process of validating the tickets, inefficiencies related to the use of subsidized tariffs, restrictions on imposing order in the port, and improper management - information basis to support the management process at all levels. Implementation or improvement in these functions depends, however, on the organizational and technological requirements that must be developed and integrated into a suitable control mechanism.

\section{Improvement of the system by using information technology}

The information system to support public coastal liner services should be developed as an integrated, processoriented business information system that contains all the elements needed to manage business processes at all levels. Regardless of whether the functioning of the procedures for acceptance of vessels is supported by an integrated information system, the ability to access and interact with a part of the coastal transport service system relating to the movement of ships will represent a signifi- 
cant improvement, both in organizational and documentation terms. This will mean a unique, controlled, accurate and timely source of information for all stakeholders that operate within the seaport. The Port Authority possessing the information system which supports the process of vessel acceptance (for example a Port Community System) should ensure the automatic data exchange and interaction between the two systems.

The Port Community Systems are complex systems created in order to concentrate, centralize, serve and optimize business processes within port communities [9]. They are information and communication models of interoperation between stakeholders included in functioning of a port, comprised of public and private participants [4]. Connecting the Port Community in a unique information community by integral ICT system implementation is a necessary step in the future operations of Croatian ports [8]. Only if all participants in the seaport system synchronously perform their duties it is possible to achieve port services of high quality [10].

The repository of vessel movement and acceptance and port state reports are subject to the interaction of Maritime coastal liner traffic information system and the Port Community System. In addition, the Maritime coastal liner traffic information system (based on ticket sales and records of passengers and vehicles, as well as financial information that binds to this category) generates the amount of port fees, in the event that it is determined as a percentage of the ticket price.

Due to large quantities of operational data that are inherent to the coastal liner passenger traffic, and consequently a request for dynamic feedback, information technology and integrated information systems are becoming a necessity in terms of data processing and the formation of appropriate control and reporting bases. The system should be structured in a way that supports:

- clearly defined flow of information,

- transfer of rules from management/control elements to the operational elements of the system.

At this level, standardization and rule setting are a prerequisite for uniform functioning and the centralization of the service process network. This service process network consists of the basic process (transport of passengers and vehicles), and support processes; reservations, sales and vessel records. Suitable structured information system is a prerequisite for the functioning of the common management level. In addition, the flow of information must comply with the levels of authorization and decision-making centres.

\subsection{The necessary adaptations of the system elements of the public coastal liner shipping in order to increase system functionality}

Certain organizational requirements should be noted in regard to centralization and integration supported by information technology, which relate to:
- the introduction of "trip" as the basic organizational/ documentation system unit,

- organization of the registration process prior to boarding,

- the introduction of attribute "possibility of booking" as mandatory for the line/trip,

- a unique timetable (for all shipping companies) posted on the official website and available via web services,

- proving the right to use the subsidized tariff by identification cards,

- the issuance of identification cards for the right to subsidies according to the strict rules, under the system for the allocation and use of preferential tariffs' rights.

\subsection{The development of management tools by information system implementation}

The instruments of public coastal liner shipping system management which are being developed as a part of system ICT enablement fall into two basic categories:

- management reporting support,

- the integration of all system elements by ensuring their interaction via set principles, by using information technology.

The required reporting background which forms the basis for establishing the dynamic connections between the planned values and feedback values consists of the following groups of reports (on management level):

- the number of passengers and vehicles per line/trip (per period);

- occupancy per line/trip/season,

- amount of support on behalf of the right to subsidized lines, income by categories (trips, lines, shippers, ships),

- statistical data relating to traffic and revenue.

\subsection{Improvement of public coastal liner shipping services by information technology implementation}

Some objectives within the computerization of the system are to simplify the sale of tickets by increasing the number of outlets, the introduction of new purchasing channels, and new means of payment. In order to increase service quality and efficiency in relation to the sale in stores and limited number of ticket agencies (according to the principle of allotment) the purchase of tickets should be adapted to customer requirements. This implies different means of purchasing. Computerization will (in addition to the increased number of traditional teller outlets) allow web purchasing, web kiosk purchasing, mobile phone purchasing, and purchasing via prepaid cards. Trip planning is connected with the possibility of booking the ticket, which will become possible for all lines based on an integrated information system. 
Table 1 Line categorization criteria

\begin{tabular}{|l|l|l|l|l|}
\hline \multicolumn{1}{|c|}{$\begin{array}{c}\text { Lines according to } \\
\text { significance }\end{array}$} & \multicolumn{1}{|c|}{$\begin{array}{c}\text { Lines according to } \\
\text { transport type }\end{array}$} & $\begin{array}{c}\text { Lines according to reservation } \\
\text { and boarding procedure }\end{array}$ & $\begin{array}{c}\text { Lines according to } \\
\text { transport period }\end{array}$ & $\begin{array}{c}\text { Lines according to } \\
\text { reservation possibilities }\end{array}$ \\
\hline State & Ferry line & Possibility of procedure organization & Seasonal & Reservation possibility \\
\hline County and intercounty & High speed line & No procedure organization & Out of season & No reservation possibility \\
\hline Local & Classic line & & & \\
\hline
\end{tabular}

With the introduction of the information system, notification and boarding can be based on the travel ticket. It is necessary to provide the technical basis for database access and ticket control (Table 1). The bearer of this activity can be the port operator or the shipper.

Lower management system levels should support the process of transport service delivery. Since the shippers are the carriers of this process, the management and administration of this part of the information system is assigned to them. It is the management of the fundamental process (execution of transport service) and support processes (reservations and ticket sales, as well as vessel tracking and logging).

Information support to the transport service processes consists of a control section and the section which supports operational activities. The control section refers to the management of reservations and ticket sales, vessel announcements and the records of vessel tracking/movement. Each shipper that has signed a concession agreement with the Coastal Liner Service Agency shall have the right to administer their own administration area within this system level, which will enable the shipper to manage reservations and ticket sales for the lines and trip for which the concession has been issued. Support of operational activities refers to the process of booking and selling, and the process of transport service execution. The needs for information - reporting background within the system of transport service are:

- pperational characteristics of the trips; time, ship capacity,

- sold and reserved tickets, the number of remaining places,

- number of loaded/transported passengers and vehicles/voided tickets.

The boarding is organized and conducted by the shipper. During boarding, the control of tickets is performed, and boarding is granted based on the valid ticket. With the introduction of an integrated information system, and with the appropriate technical prerequisites, this procedure can be performed by accessing the database using handheld devices.

Thus organized and ICT supported procedures of embarkation provide real-time reporting related to travel operational data. Data related to the course of embarkation and the like is readily available. This data can have a very important role regarding the security issues. Ticket checking and validation during the embarkation means dual control, reducing the possibility of abuse.
The most general and highest level of the information systems refers to setting the basic rules of functioning, as a prerequisite for managing, supervision and control of the described operational levels. The instruments of the management level are the requirements for the transfer of policies through the implementation of basic processes within the information system:

a) Within the system administration:

- granting of permission to access and use,

- the organization of links between documents,

- the organization of communication channels/information flow.

b) Within the implementation of common rules and standardization - the rules that are set on the top and middle management levels:

- establishment of the timetable,

- establishment of shipping lines,

- establishment of trips,

- operationalization of trips,

- formation of announcements,

- determination of the season and post-season,

- determination of the rules for the use of subsidized tariffs.

According to the business functions and purposes, the holder of the majority of the activities within the highest and middle management levels is the Coastal Liner Service Agency. Due to the modularity of the links between system elements, these activities can be easily distributed among other carriers, depending on which roles are assigned to which entities within the system. An integrated information system that includes the conceptual and operational level, with the participation of all of stakeholders, is a prerequisite for achieving an acceptable level of operational and management efficiency of the transport system.

Quality process management implies clearly defined inputs and outputs, as well as control points through the course of the process, and interaction points between the processes. A large quantity of operational data and the dynamic requirements at the operational level underline the importance of information base, which allows the use of information in real time. Suitably designed reports are an instrument for effective process management, when the criteria of reporting are applied in accordance with the measurement criteria. 


\section{Conclusion}

From the complexities of the public coastal liner shipping, and the inclusion of a large number of stakeholders (users, regulators, coordinators at different management levels), multiple effects arise which can affect the overall efficiency. By computerizing the Coastal Liner Service Agency, a firm and integrated management system can be achieved. This system will be designed to support centralized management principles, covering about 90 ports and over 50 national lines. The support is also possible for the county, inter-county and local lines. This is the basis for the development of mechanisms and tools of operational and strategic management, disposal and use of data in real time, controlling the system of awarding and exercising the right to subsidized tariffs, increasing the quality of services, providing statistics on traffic and revenue, and increasing the efficiency of the business processes of the Agency. For shippers, the introduction of integrated information system means the development of mechanisms and tools for managing business, the availability of information needed to manage the process of service execution, more efficient and cheaper process of reservations and ticket sales, increased service quality, increased ability to control the use of subsidized tariffs, and consequently, an increase in revenue from ticket sales.

Since it is a public system, its computerization has a much wider impact; benefits will occur for a number of institutions in the form of availability of statistical reports on various categories and criteria. For the national economy and society, the computerization of public transport services means an efficient and controlled transport subsystem as an important factor in the efficiency of the overall national economy, the ability to monitor development trends and the use of performance indicators as instruments of strategic management.

\section{References}

[1] Act on Classification of Public Ports in Dubrovnik-Neretva County, Official Gazette, No. 32, 2011.

[2] Act on Maritime Domain and Seaports, Official Gazette, No. 158, 2003, No. 141, 2006, No. 38, 2009.

[3] Act on Transport in Liner Shipping and Occasional Coastal Maritime Traffic, Official Gazette, No. 33, 2006, art. 4.

[4] Aksentijević, S., Tijan, E., Hlača, B.: Importance of Organizational Information Security in Port Community Systems, MIPRO 2009, Proceedings of $32^{\text {nd }}$ International Convention on Information and Communication Technology, Electronic and Microelectronics.

[5] ISO 9000:2000; Quality Management System - requirements, http://www.iso.org/iso/.

[6] Jugović, A., Bistričić, A., Debelić, B.: Economic Effects of Privatisation of Public Services Sector in the Republic of Croatia Emphasising Maritime-Passenger Traffic, Ekonomska istraživanja, Vol. 23, No. 4, 2010.

[7] Stupalo, V., Jolić, N., Jugović, A.: Opportunities of Passenger Liner Shipping Development in Croatia, Proceedings of the $7^{\text {th }}$ International Conference on Ports and Waterways POWA 2012.

[8] Tijan, E., Agatić, A., Hlača, B.: Port Community System Implementation in Croatian Seaports, Promet/Traffic \& Transportation, Vol. 24, No. 4, 2012.

[9] Tijan, E., Aksentijević, S., Čišić, D.: Disaster Recovery and Business Continuity in Port Community Systems, Scientific Journal of Maritime Research, Vol. 23, No. 1, Rijeka, 2009.

[10] Tijan, E., Hlača, B., Agatić, A.: Port Community System - a Trade Facilitator for Croatian Seaports, Proceedings of Conference on International Trade, Education and Marketing CITEM, 2011. 